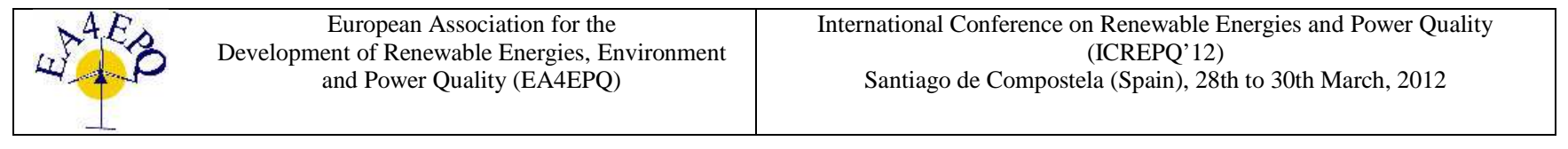

\title{
Use of Newton's Method for Rotor-Resistance Control of Wind Turbine Generators
}

\author{
A. F. Bastos ${ }^{1}$, E. F. Cota ${ }^{1}$, S. R. Silva ${ }^{2}$, H. A. Pereira ${ }^{1,2}$ \\ ${ }^{1}$ Department of Electrical Engineering, Universidade Federal de Viçosa \\ Av. P.H.Rolfs s/n,36570-000, Viçosa, MG, Brazil \\ Phone: +55-31-3899-3266 \\ ${ }^{2}$ Graduate Program in Electrical Engineering - Universidade Federal de Minas Gerais \\ Av. Antônio Carlos 6627, 31270-901, Belo Horizonte, MG, Brazil \\ Phone: +55-31-3409-4842
}

E-mails: alvarofurlani@hotmail.com,edmar-ferreira@hotmail.com, selenios@dee.ufmg.br, heverton.pereira@ufv.br

\begin{abstract}
The advancement in the use of renewable sources of electricity has been promoting the manufacture of wind turbines. This paper analyzes the influence of the insertion of resistance in the rotor of induction machines during voltage sags to improve its operation and presents a new approach. The control strategy uses the Newton's Method, which is a numerical method. A simulation in a wind generator was realized, proving the control efficiency.
\end{abstract}

\section{Key words}

Newton's Method, Induction Machine, Voltage Sags, Rotor Resistance, Speed control.

\section{Introduction}

Due to the increasing global demand for energy consumption and growing emissions of greenhouse gases, which have a great responsibility on global warming, many governments around the world have invested in power generation from renewable sources.

The use of wind energy for electricity generation is currently one of the most frequently used renewable energy sources and presents an increasing projection for its applications in the future.

There are various types of generators used in conjunction with the wind turbine. The most commonly used is the asynchronous generators, because they can be easily built, they are not too much expensive and require no timing devices.

Many turbines have an asynchronous generator directly connected to the grid, where it determines the rotation frequency of the generator. This configuration is simple, but it is very sensitive about sudden changes of wind. If the grid has a low level of short circuit, these variations can influence to the grid.
It's possible to get a way for improvement the energy quality generated in wind turbines by using a wound rotor induction generator, as seen in Fig. 1.

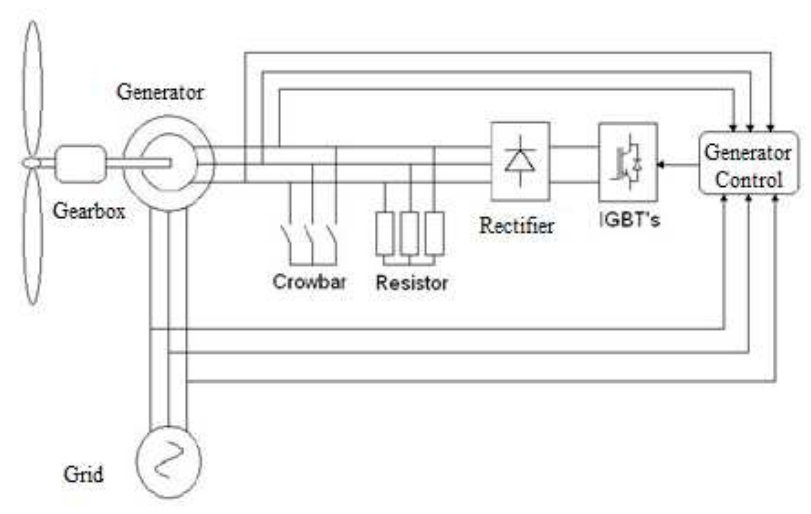

Fig. 1 - Wound Rotor Induction Generator [1].

This configuration has the advantage of controlling the speed of the generator by varying the slip, which is obtained by varying an external resistance connected at generator rotor.

An numerical method, using the Newton`s Method, is used to control the external resistance switching. Therefore, the torque generator keeps in its nominal value.

\section{Electrical Grid Problems}

There are many ways of evaluating the quality of electricity supply. We can mention the continuity of supply level, voltage fluctuations, unbalance, voltage harmonic distortion and interference in communication systems.

Some disorders that occur most frequently are listed below. 
- Flicker: flickering light, found primarily through visual impressions resulting from variations in luminous flux of lamps;

- Voltage imbalance: differences between the magnitudes of the phase voltages of polyphase circuits;

- Voltage notch: it represents the abrupt collapse of tension that occurs at each alternation; may or may not drop to zero is changes sign;

- Noise: distortion of sinusoidal voltage due to the superposition of a high-frequency signal;

- Overvoltage, voltage swell and spikes: creates an increase in voltage beyond the normal limit and it is classified as spikes, voltage swell or overvoltage, according to the time of occurrence;

- Undervoltage and voltage sag: creates a decrease in voltage beyond the normal limit and it is classified as a voltage sag or undervoltage, according to the time of occurrence;

- Harmonics: multiple frequency voltages are the fundamental frequency of the generated voltage. It causes increasing losses and distortions in the voltage supplied by the generator.

Any abrupt variation of the voltage grid can cause electrical and mechanical damage in a wind turbine and disconnection from electrical system.

\section{Brazilian and German Standards}

Beside the increasing use of wind energy to generate electricity and large-scale entry of this energy source in power generation systems, regulatory agencies and energy operators has been forced to edit their grid procedures concerning the relationship and integration between grid and wind farms.

The grid codes are intended to define the conditions for the operation of power generators to ensure stability and reliability in energy supply [2]. One of the main requirements on wind energy is to support the LVRT (Low Voltage Ride Through) defined by IEC 61000-82. This condition is about the continuous operation of wind generators even in a voltage drop while a given time interval. The values of voltage drop and the time interval of this decline varies according to the regulations of each country. Fig. 2 and Fig. 3 show the minimum requirements of operation for wind turbines in Germany and Brazil, respectively.

Comparing Fig. 2 and Fig. 3, it's easy to notice some changes of the grid code between countries, but the variations of the curves in LVRT remain similar. In other words, large voltage sags can occur only at intervals no longer than 1 second, but the occurrence of undervoltage smoother has a larger tolerance.

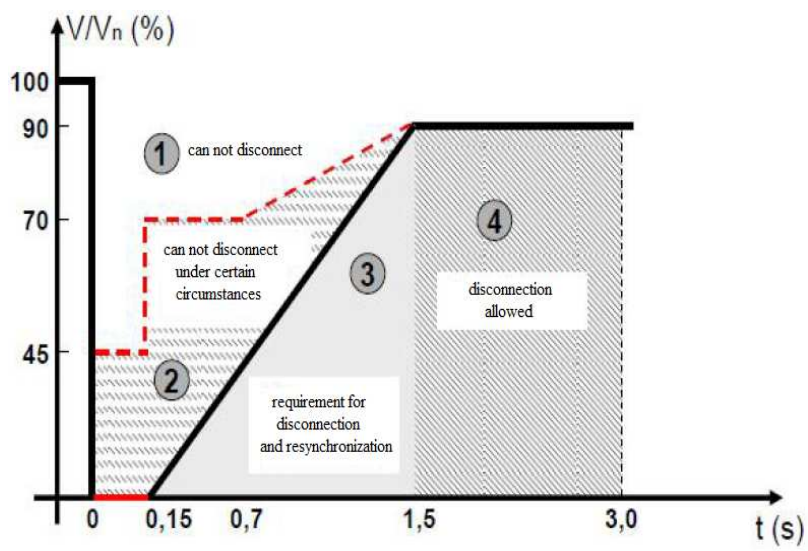

Fig. 2 - Voltage sags that the wind turbine must withstand the German grid code.

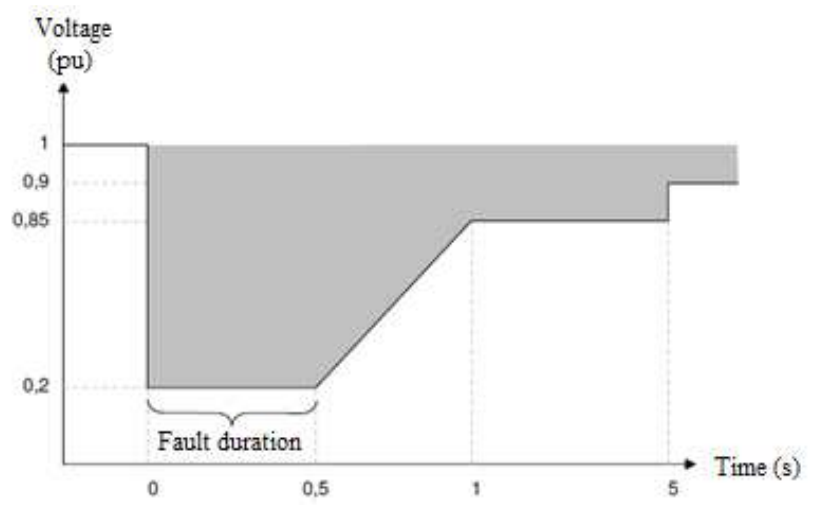

Fig. 3 - Voltage sags that the wind turbine must withstand the Brazilian grid code [2].

In 2009, it was launched in Brazil the Grid Procedures, which are normative documents drawn up by the ONS (National Electric System Operator). It contains the basic procedures for grid connection. Sub-module 3.6, entitled "Minimum technical requirements for connection to a primary", presents the minimum criteria that wind generators must satisfy. In the case of momentary voltage sags, Fig. 2 shows the relationship between the percentage of subsidence and fault duration for which the turbine must remain connected to the grid.

The purpose of these criteria is to make the generation from wind farms can contribute with the system to withstand momentary voltage sag without disconnection from the grid.

\section{Newton's Method}

Newton's Method is a particular case of a linear interaction method, in order to estimate the roots of a function $f(x)$ by using an iterative process. Fig. 4 demonstrates the application of this method. 


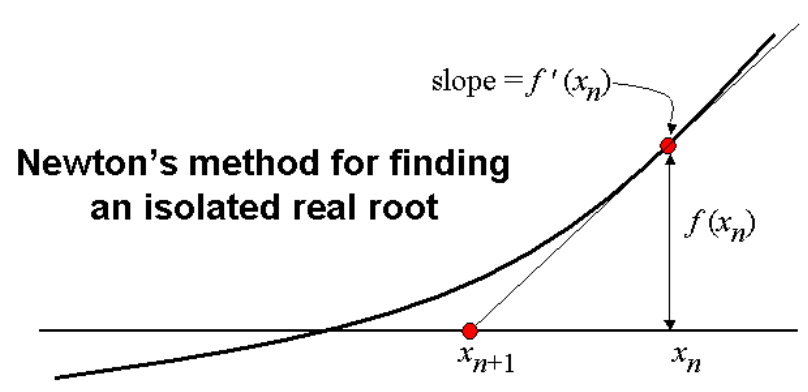

Fig. 4 - Newton's Method.

According to Fig. 4, the line tangent to the function $f(x)$ at point $x_{n}$ is given by:

$$
f^{\prime}\left(x_{n}\right)=\frac{f\left(x_{n}\right)-0}{x_{n}-x_{n+1}} \rightarrow x_{n+1}=x_{n}-\frac{f\left(x_{n}\right)}{f^{\prime}\left(x_{n}\right)}
$$

To determine the value of $x_{n+1}$, apply Fig. 4 again to a further approximation of the root of the function. Therefore after each iteration performed, there is an approximation to the value where the function takes the value zero.

Still looking at Fig. 4, it is apparent that the approximation process will be faster if $x_{n}$ is closer to the root of the function, indicating that the initial value is important for the speed of convergence of this method.

To ensure the convergence of the Newton's method is necessary to determine an interval $[\mathrm{a}, \mathrm{b}]$, where $f(a)<0$ and $f(b)>0$, or, $f(b)<0$ and $f(a)>0$, which contains the root of $f(x)$, where $f(x)$ and $f^{\prime}\left(x_{n}\right)$ are continuous, and $f^{\prime}\left(x_{n}\right) \neq 0$ if $x_{n}$ is not the root.

The Newton's method does not find the exact value of the root, but can approximate it with any desired accuracy. Therefore it is interesting to define the relative error at each iteration in the application of the method. This is given by (2).

$$
\operatorname{Error}(\%)=\frac{\left|x_{n+1}-x_{n}\right|}{x_{n+1}}
$$

The process reaches the end of iterations when the relative error given by (2) is below a certain level of accuracy.

\section{Methodology}

The purpose of this paper is to evaluate the effect of insertion resistance in the rotor of induction machines during momentary voltage sags. The desired simulations were performed at Matlab/Simulink ${ }^{\circledR}$ software, according to the general model show in Fig. 1.

At first, the effect of inclusion of additional rotor resistance in its rotational speed is verified. Fig. 5 clearly indicates that the speed machine decreases as much as the rotor resistance increases, at nominal conditions of operation. It is possible to note that the maximum torque remains constant through the variations of the rotor resistance.

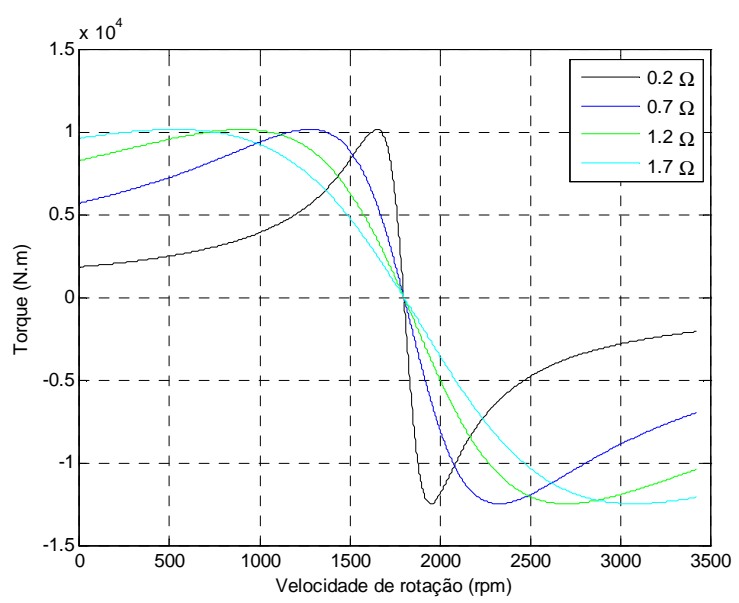

Fig. 5: Steady-state torque-speed characteristics of an induction machine of various values of rotor resistance.

Another analyzed effect is the voltage variation at machine terminal (assuming constant rotor resistance). Fig. 6 shows a reduction of torque value as long as voltage is reduced; this variation is significantly high, since the torque varies in a rate as the square of voltage.

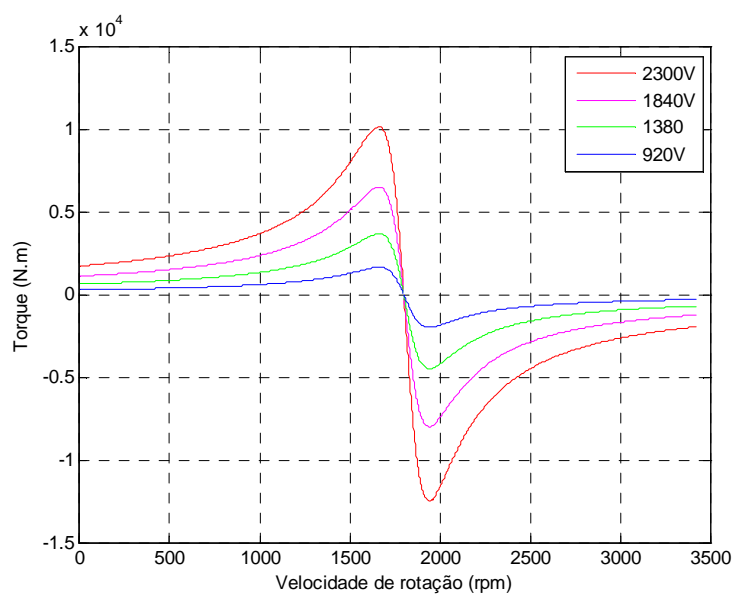

Fig. 6: Steady-state torque-speed characteristics of an induction machine of various values voltage.

The machine used was $500 \mathrm{hp}$, whose parameters are available at [5].

The voltage drop occurred between 1 and $2 \mathrm{sec}$; at $0.5 \mathrm{sec}$ initials, the voltage fell to $20 \%$ of its nominal values, $85 \%$ at the next $0.5 \mathrm{sec}$ and returned to its nominal value after $2 \mathrm{sec}$, in compliance with the Brazilian regulation on the subject.

As predicted by Fig. 6, the machine tends to accelerate during the voltage drop to maintain a constant torque. 
However, this acceleration is undesirable and according to Fig. 5 it is possible to mitigate this impact on speed by addition of resistance in the rotor. Thus, some the following will present some results regarding how the machine reacts to these situations.

The Newton's Method was used to calculate the rotor resistance required for the machine operates at its maximum torque. The value at each instant is given by (3), according to [6].

$$
T_{e m}=\frac{3 \cdot P}{2 \cdot w_{e}} \cdot \frac{V_{t h}^{2} \cdot\left(\frac{R_{r}}{S}\right)}{\left(R_{t h}+\frac{R_{r}}{S}\right)^{2}+\left(X_{t h}+X_{l r}\right)^{2}}
$$

Where:

$$
\begin{gathered}
V_{t h}=\left(\frac{j \cdot X_{m}}{R_{s}+j \cdot\left(X_{l s}+X_{m}\right)}\right) \cdot V_{a s} \\
Z_{t h}=R_{t h}+j \cdot X_{t h}=\frac{j \cdot X_{m} \cdot\left(R_{s}+j \cdot X_{l s}\right)}{R_{s}+j \cdot\left(X_{l s}+X_{m}\right)}
\end{gathered}
$$

The additional rotor resistance is represented by a threephase resistor bank; its value varies according to the IGBT, which operates based on the value of resistance provided by Newton's Method.

\section{Results}

The first simulation of the machine consists in comparing the same machine, on the same operating conditions, firstly with rotor resistance speed control and, in a second moment, without it. Fig. 7 illustrates this situation.

Firstly, it is possible to observe that the torque provided by the machine is the same before the voltage drop. Between 1 and $1.5 \mathrm{sec}$, there are no changes, because the addition of the rotor resistance is not sufficient to avoid the acceleration of the machine, since the fall in this interval is very expressive. From $1.5 \mathrm{sec}$, the voltage returns to $85 \%$ of its nominal values, but its speed continues to increase if no control is present, or gradually decreases with the resistance addition. After $2 \mathrm{sec}$, in the moment the fall is ended, the machine with control returns to its rated speed in some seconds, instead of continuing to accelerate for some time (what would happen if control has not been applied).

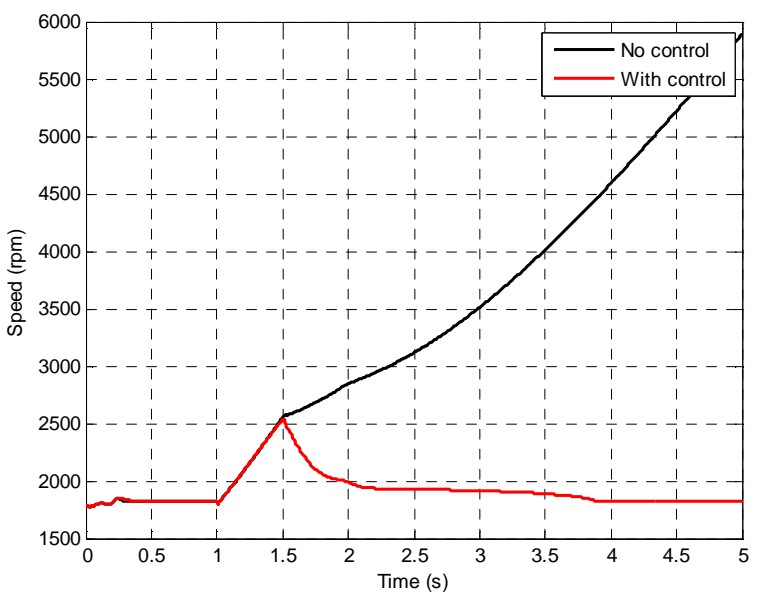

Fig. 7: Comparison between induction machine with and without speed control

Fig. 8 shows how the rotor resistance varies during the voltage drop in the speed control. Note that about $0.2 \mathrm{sec}$, there is a slight increase in resistance; this occurs due to the start of mechanical torque.

At $1 \mathrm{sec}$, the rotor resistance continuously increases, indicating the action of control in attempting to maintain constant speed.

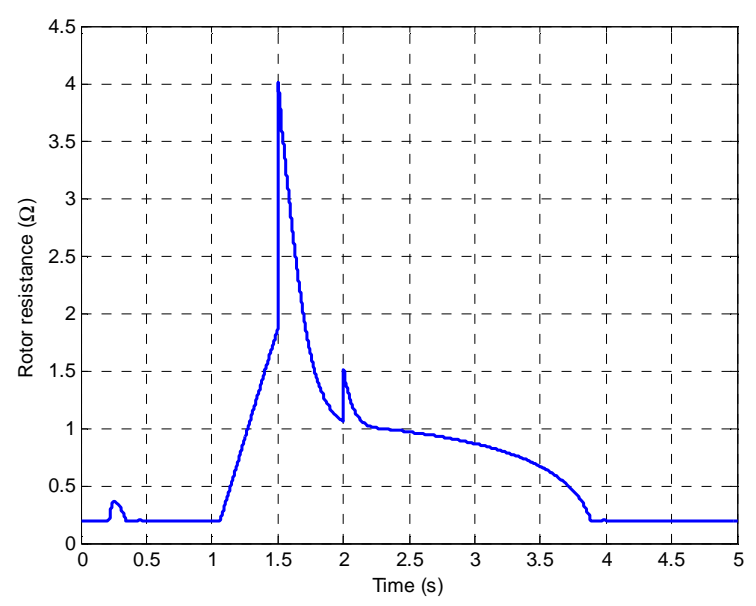

Fig. 8 - Variation of rotor resistance during voltage drop.

It is known that the increase in the voltage tends to accelerate the machine, therefore is necessary higher levels of resistance to control its speed. Thus, at $1.5 \mathrm{sec}$, when the voltage drop increases to $85 \%$ of its nominal value, there is a sudden rise in resistance.

After the end of the voltage drop, there is another sudden increase in resistance. But in this case, its value quickly decreases to reach the operation nominal value. In this situation, the additional resistors are shortcircuited. 
Fig. 9 shows the active power produced by the machine. Along the interval with the most significant voltage drop, the power output is zero. If there is not any kind of control, this values remains zero even after the voltage returns to its nominal values. However, the power output quickly reaches its nominal value $(500 \mathrm{hp}=$ $0,373 \cdot 10^{6} \mathrm{~W}$ ) if the additional rotor resistance is inserted.

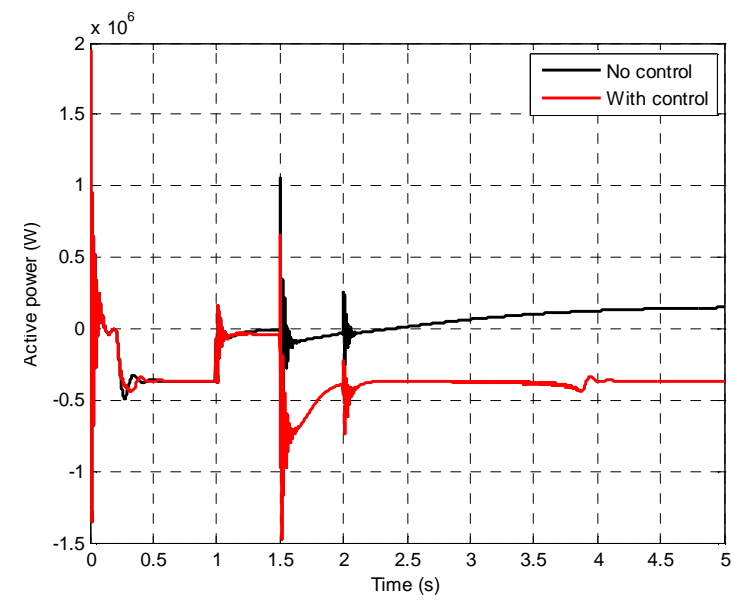

Fig. 9 - Variation of active power during voltage drop.

In Fig. 10 it is shown the reactive power consumed by the machine. Similarly to the behavior of active power, reactive power returns to zero in a short time after the voltage drop when the speed control is used. In the other hand, this value remains relatively high if no control is used.

Fig. 11 shows the RMS value of the stator current. Again, it is possible to perceive the influence of increase rotor resistance in the machine operation subjected to voltage drop. The presence of the control system caused the fast reduction of current to its nominal value. It should be noticed that during the voltage variation, high currents occur in the machine; this effect is very important for a proper design of the machine.

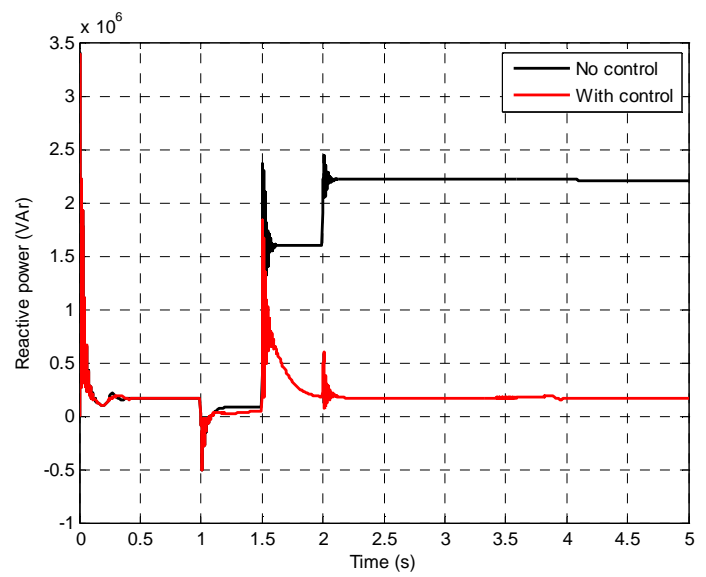

Fig. 10 - Variation of reactive power during voltage drop.

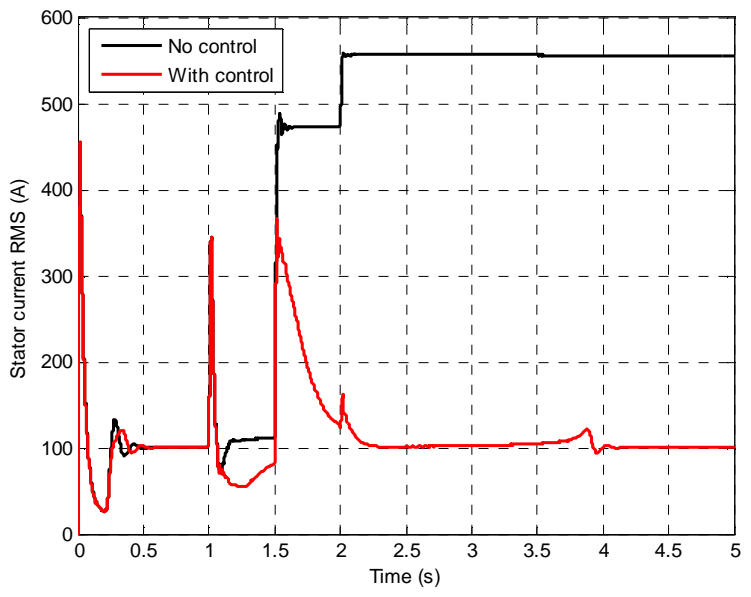

Fig. 11 - Variation of stator current during voltage drop.

The previous analysis observed that insertion of resistance in the rotor during voltage drop produces improvements in machine operation. However, this method of speed control has some limitations. For instance, its effects are significant only for short duration sags.

In fact, according to Figure 12, which compares sags with different durations, the machines takes longer to regain his speed as longer the voltage drop is. It is also clear that the rotor resistance cannot prevent the machine acceleration in situations where the fall is very significant (between 1 and $1.5 \mathrm{sec}$ ); its greatest utility corresponds to the situation where the voltage returns to its nominal value after the sinking and generator speed decreases.

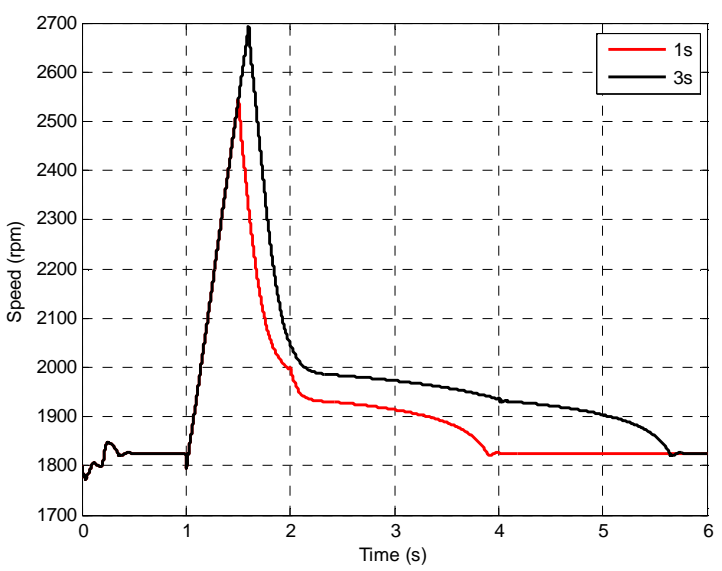

Figure 12 - Comparison for different sag duration

\section{Concluding Remarks}

The analyzes performed in this study is useful to check the impact of insertion of resistance in the rotor during momentary voltage sags. It is an effective method for controlling speed for short voltage drops, enabling the 
machine to quickly recover its nominal operation speed and avoiding the emergence and persistence of very high currents.

In situations prolonged voltage drops the speed control by inserting rotor resistance is not efficient. These cases the protection system must action to prevent high speeds in generator.

\section{References}

[1] Hansen, Anca D, Hansen, Lars H.; "Market penetration of wind turbine - concepts over the years", European Wind Energy Conference and Exhibition. Italy, 2007.

[2] ONS, "Procedimentos de Distribuição (PRODIST)", Module 8: Power Quality.

[3] Mohamed Ridha Khadraoui, Mohamed Elleuch, "Comparison between OptiSlip and Fixed Speed Wind Energy Conversion Systems", $5^{\text {th }}$ International MultiConference on Systems, Signals and Devices, 2008.

[4] Bollen, M.H.J., "Characterization of Voltage Sags Experienced by Three-Phase Adjustable-Speed Drives", IEEE Transactions on Power Delivery, vol. 12, no. 4,October 1997.

[5] Krause, P. C., Wasynczuk, O., \& Sudhoff, S. D.; "Analysis of Electric Machinery and Drive Systems" (2 $2^{\mathrm{a}}$ ed.). Wiley-Interscience.

[6] Ong, C.-M.; "Dynaminc Simulation of Electric Machinery". 